\title{
Assessment of the biodegradation capacity of Azolla on polycyclic aromatic hydrocarbons in crude oil
}

\author{
Kösesakal T.* \\ Department of Botany, Faculty of Science, Istanbul University, 34134 Süleymaniye, Istanbul, Turkey \\ Received: 07/12/2017, Accepted: 13/7/2018, Available online: 26/09/2018 \\ *to whom all correspondence should be addressed: e-mail: taylank@istanbul.edu.tr \\ https://doi.org/10.30955/gnj.002544
}

\begin{abstract}
In this study, the potential use of Azolla filiculoides Lam. for the bioremediative solution to polycyclic aromatic hydrocarbon (PAH) pollution due to crude oil spills in freshwater was investigated. The plants were grown in nitrogen-free Hoagland nutrient solution media containing $0.05 \%, 0.1 \%, 0.2 \%, 0.3 \%, 0.4 \%$ and $0.5 \%$ crude oil by volume for 15 days under greenhouse conditions. Relative growth rates of $A$. filiculoides decreased in the presence of crude oil in a concentration-dependent manner. The probable influence of $A$. filiculoides on the biodegradation of polycyclic aromatic hydrocarbons was measured by using synchronous UV fluorescence spectroscopy. GC-MS analysis were also carried out to elucidate the behavior of the oil in experimental and control samples. Although 1-2 rings PAHs have not been encountered in control or plant samples, the measured intensity for 3-4 ring PAHs in plant samples was remarkably lower in comparison to the control. Furthermore, these results demonstrated that the predominant efficacy of the A. filiculoides was for 3-4 ring PAHs at the range 0.05 to $0.2 \%$ crude oil concentrations. It could be concluded that the bioremediative potential of A. filiculoides for the removal of polycyclic aromatic hydrocarbons strongly depends on the amount of oil in the contaminated water resource. In other words, $A$. filiculoides could be used more effectively after the removal of excess crude oil in the spilled freshwater areas.
\end{abstract}

Keywords: Azolla, biodegradation, crude oil, PAHs, Relative growth rate.

\section{Introduction}

Crude oil has been a veritable source of economic growth to modern societies from the point of view of its energy and industrial importance (Okoh, 2006). Moreover, increased energy demand places crude oil among the major issues for the next two decades (Aljuboury et al., 2017). Petroleum is a complex mixture of $n$-alkanes, aromatics, resins and asphaltenes. Many of these components are toxic, mutagenic and carcinogenic (Propst et al., 1999; Zappi et al., 1996). Natural crude oil contains significant amounts of polycyclic aromatic hydrocarbons (PAHs). PAHs are composed of two or more aromatic (benzene) rings. Because of their bioaccumulation potential and carcinogenic activity, they have gathered significant environmental concern. (Haritash and Kaushik, 2009). Therefore, their release to the environment is strictly controlled. Because of exponential increase in worldwide oil consumption, more frequent oil tanker accidents, and occasional leaks from oil pipelines, petroleum hydrocarbons have become one of the most abundant and harmful pollutants in soil and water resources (Mrayyan and Battikhi 2005; Vasudevan and Rajaram, 2001). In return, this fact has necessitated the development of new techniques for the removal of contaminants (Millioli et al., 2009). Phytoremediation is an emerging and the most promising technology, defined as the use of plants and associated microorganisms to remove, transform, stabilize, volatilize or assimilate toxic chemicals located in soils, water and air via various biochemical process (Jagtap et al., 2014; Rajkumar et al., 2013).

There is an increasing number of studies that evaluate the use of plants in the petroleum contaminated freshwater areas and in these researches different plant species such as Landoltia punctata (Ertekin et al., 2015), Vetiveria zizanioides (Effendi et al., 2017) and Lemna minor (Wang et al., 2017) have been used. Azolla has a special significance between the freshwater plants used in phytoremediation. It is a fast growing species and can double it's biomass in 5 to 10 days (Kollah et al., 2016) and for these reason Azolla is often used in phytoremediation studies (De et al., 2017; Gomes et al., 2018; Kosesakal et al., 2016).

The main purpose of this study was to elucidate the biodegradation potential of a freshwater fern species, Azolla filiculoides, on polycyclic aromatic hydrocarbons in crude oil.

\section{Materials and methods}

\subsection{Cultivation of plants and application of crude oil}

Azolla filiculoides plants were grown in nitrogen-free Hoagland nutrient solution $26-28^{\circ} \mathrm{C}$ under greenhouse conditions. In this study, crude oil from Batman Refinery 
(Batman, Turkey) was used. The effect of different amounts of crude oil $(0.05 \%, 0.1 \%, 0.2 \%, 0.3 \%, 0.4 \%$ and $0.5 \%$ by volume, for 15 day) on the growth of Azolla filiculoides was investigated. Oil applications were done as follows: The crude oil $0.005 \% 0.01 \%, 0.05 \%, 0.1 \%, 0.2 \%$, $0.3 \%, 0.4 \%$ and $0.5 \%$ concentrations $(\mathrm{v} / \mathrm{v})$ were added into glass beakers $(500 \mathrm{ml})$ containing $\mathrm{N}$-free Hoagland nutrient solution. The beakers containing different oil concentrations containing $\mathrm{N}$-free Hoagland nutrient solution used as negative control. 24 hours after the application of crude oil, 3 grams of plants were weighed from each experimental series and left to grow under greenhouse condition for another 15 days before the finalization of the experiment. All the experiments were performed with three replicates.

\subsection{Analysis of plant growth}

A. filiculoides relative growth rate (RGR) $\left(g^{-1} \mathrm{~d}^{-1}\right)$ was calculated by the formula;

$R G R=(\ln W 2-\ln W 1 / t$, where $W 1$ and $W 2$ are the initial and final fresh weights, and $t$ is the experimental time (Jampeetong and Brix, 2009).

\subsection{Extraction and clean-up}

To evaluate the degree of hydrocarbon degradation, liquid/liquid extraction was applied to the experimental growth media was employed with (DCM) dichloromethane (U.S. EPA, METHOD 3510C). After the termination of each crude-oil applications, the plant samples were taken from the experimental growth mediums, according to U.S. EPA METHOD 3541 automatic Soxhlet extraction (SER 6 VELP) was applied. 2fluorobiphenyl (Dr. Ehrenstorfer, Germany) was added as internal standard. The extracts obtained from the samples according to U.S. EPA METHOD $3600 \mathrm{C}$ by column chromatography to be divided into 2 fractions as aliphatic and aromatic groups. Total extracts were fractionated by applying to Fluorosil columns. In brief, the extracts ( 0.5 to $1 \mathrm{ml}$ ) was added carefully and the column fractions were collected: (1) $10 \mathrm{ml}$ of hexane (aliphatic hydrocarbons), and (2) $10 \mathrm{ml} \mathrm{1:1} \mathrm{dichloromethane:} \mathrm{hexane} \mathrm{(aromatic}$ compounds). The extracts were concentrated to 100 microliters under the nitrogen gas flow.

\subsection{Analysis of petroleum hydrocarbons}

Total petroleum hydrocarbons ( $\Sigma \mathrm{TPH})$ were analyzed by UV fluorescence (UVF) spectroscopy (RF-5301, Shimadzu). The samples were diluted to within the linear calibration range of the spectrofluorometer. Excitation and emission wavelengths were fixed to 310 and $360 \mathrm{~nm}$ for single measurement, respectively. The calibration curves were plotted in the range of $0.25-2 \mu \mathrm{g} \mathrm{oil} / \mathrm{ml}$ hexane (Ehrhardt et al., 1992). The measurements were assured to be within the linear calibration range of the spectrofluorometer for Batman crude oil.

\subsection{Spectrofluorometric analysis of PAHs}

The samples were analyzed by synchronous UV fluorescence spectroscopy (SUVF, Jasco-6300, Shimadzu).
For quantitative characterization, the excitation wavelengths scanned were at covered the range from 220 to $700 \mathrm{~nm}$. The $\Delta \lambda$ interval between $\lambda_{\mathrm{ex}}$ and $\lambda_{\mathrm{em}}$ was constant and equal to $23 \mathrm{~nm}$ (Lloyd, 1971). Each sample was analyzed in triplicates in order to evaluate the reproducibility of the method. One $\mathrm{cm}$ length quartz cuvettes were used for the measurements.

\section{6. $G C / M S$ analysis}

GC/MS analysis were performed with Perkin Elmer Thermo DSQ Turbo MSD system. The extracts were analyzed in splitless mode by using a fused silica capillary column HP-5 MS (30 m×0.25 mm ID $\times 0.25 \mu \mathrm{m}$ film thicknesses) and helium ( $1 \mathrm{ml} / \mathrm{min})$ as carrier. The front inlet temperature was $280^{\circ} \mathrm{C}$ and the injector was set for splitless injection. The $\mathrm{GC}$ oven temperature was programmed from $50^{\circ} \mathrm{C}$ (held for $1 \mathrm{~min}$ ) to $320^{\circ} \mathrm{C}$ at a rate of $10^{\circ} \mathrm{C} \mathrm{min}-1$ and maintained at $320^{\circ} \mathrm{C}$ for $5 \mathrm{~min}$. The MS temperature program for transfer line was $220^{\circ} \mathrm{C}$. The MS was operated in El mode (70 eV) scanning from 50 to 600 amu. The library search was carried out using Wiley and NIST GC/MS library. The GC/MS was calibrated for aliphatic hydrocarbons (n-alkanes calibration mixture purchased from Dr. Ehrenstorfer, Germany) from $\mathrm{nC}_{10}$ to $\mathrm{nC}_{35}$ and the selected PAHs by using the internal standard calibration procedure described in US EPA Method 8000 and 8015 respectively. All of the solvents were of HPLC grade.

\subsection{Statistical analysis}

All the experimental data were obtained in 3 replicates. The experimental results are expressed as mean \pm standard deviation (SD) of triplicate measurements and analyzed. Statistical analysis was performed using GraphPad Prism version 5.2 for windows (GraphPad Software, San Diego, CA). Significant differences between the means were determined by the the Dunnett's Multiple Comparison Test and Tukey's Multiple Comparison test.

\section{Results and discussion}

\subsection{Plant growth}

The relative growth rate of the control plants was $0,148 \mathrm{~g}$ $\mathrm{g}^{-1} \mathrm{~d}^{-1}$ at the end of the 15-day experimental period (Table 1). While RGR slightly impeded at $0.05 \%$ and at $0.1 \%$ oil concentrations, the oil concentration above $0.2 \%$ noticeably reduced the growth rate (Table 1 ). In this study, plant growth was inhibited in a dose dependent manner. Furthermore, our results indicate crude oil concentrations $>0.2 \%$ had a negative effect on plant growth by reducing RGR values. This is consistent with previous reports of the effect of diesel and crude oil on the RGRs of S. grossus (Al-Baldawi et al., 2015) and L. punctata (Ertekin et al., 2015) respectively. The hindering effect of oil on plant growth could be as a result of the phytotoxicity of the increased number of aromatic rings (Baek et al., 2004). Thus it could be stated that crude oil 
increased in growth inhibition effect according to their concentration and number of aromatic rings

Table 1. Relative growth rates of $A$. filiculoides treated with different crude oil concentration. " \pm " indicates standard deviation. Significant differences were determined by Tukey's multiple comparison test $(\mathrm{P}<0.05)$ and are indicated by different letters.

\begin{tabular}{cc}
\hline (\%) Crude oil & RGR $\left(\mathbf{g ~ g}^{-1} \mathbf{d}^{-1}\right)$ \\
\hline Control & $0.148 \pm 0.005^{\mathrm{a}}$ \\
\hline $\mathbf{0 . 0 5}$ & $0.138 \pm 0.004^{\mathrm{b}}$ \\
\hline $\mathbf{0 . 1}$ & $0.124 \pm 0.001^{\mathrm{c}}$ \\
\hline $\mathbf{0 . 2}$ & $0.104 \pm 0.004^{\mathrm{d}}$ \\
\hline $\mathbf{0 . 3}$ & $0.075 \pm 0.006^{\mathrm{e}}$ \\
\hline $\mathbf{0 . 4}$ & $0.067 \pm 0.007^{\mathrm{e}}$ \\
\hline $\mathbf{0 . 5}$ & $0.073 \pm 0.001^{\mathrm{e}}$ \\
\hline
\end{tabular}

\subsection{Total petroleum hydrocarbons ( $\Sigma T P H)$}

To determine the relative change in the amount of total petroleum hydrocarbons as a result of the application of plants at different oil concentrations, $\Sigma T$ TPH was measured from negative control media, plant growth media, and plant material by UVF (Table 2). TPH amounts obtained from the plant-free growth medium (negative control) increased, as expected, depending on the applied concentrations of oil $(0.05 \%, 0.1 \%, 0.2 \%, 0.3 \%, 0.4 \%$ and $0.5 \%)$. On the other hand, the amount of TPH in growth media with the plants was remarkably decreased relative to the control media at the end of 15-day application period (Table 2). As also expected, the amount of TPH in plants were also increased with the increase in the percentages of oil (Table 2). Huang et al. (2005) reported that the amount of removed TPH from soil was different for different systems ranging from $90 \%, 55 \%, 40 \%$, and $20 \%$ for multi-process phytoremediation, phytoremediation, bioremediation and land-farming respectively at the end of the 8 months. It could be suggested that degradation of TPHs is likely to be as a result of physical, chemical and biological actions all together. In the unplanted control areas, the degradation is often caused by volatilization and photolysis (Peng et al., 2009). In this study, TPH amounts obtained from the planted growth media were significantly $(p<0.05)$ less with respect to the unplanted control media (Table 2).

Table 2. The values of $\Sigma T P H$ obtained from the negative control and the growth media with plants and the plant samples at different crude oil concentrations (0.05\%-0.5\%) after 15 days of growth. " \pm " indicates standard deviation. Significant differences determined by the Tukey's Multiple Comparison test $(p<0.05)$ are indicated by different letters. "*” indicates significant difference from negative control media. Significant differences determined by the Dunnett's Multiple Comparison Test $(p<0.05)$.

\begin{tabular}{cccc}
\hline \multicolumn{4}{c}{ Total Petroleum Hydrocarbons Amounts $(\Sigma \mathrm{TPH})$} \\
\hline (\%) Crude Oil & Control Media $(\mu \mathrm{g} / \mathrm{ml})$ & Plant Media $(\boldsymbol{\mu g} / \mathrm{ml})$ & Plant $(\mu \mathrm{g} / \mathrm{gFW})$ \\
\hline $\mathbf{0 . 0 5}$ & $1151.40 \pm 86.76^{\mathrm{e}}$ & $6.24 \pm 0.47^{\mathrm{d} *}$ & $448.86 \pm 87.57^{\mathrm{d} *}$ \\
\hline $\mathbf{0 . 1}$ & $1510.75 \pm 113.83^{\mathrm{e}}$ & $12.68 \pm 0.96^{\mathrm{d} *}$ & $1152.54 \pm 139.86^{\mathrm{cd} *}$ \\
\hline $\mathbf{0 . 2}$ & $9150.52 \pm 689.45^{\mathrm{d}}$ & $14.30 \pm 1.08^{\mathrm{d} *}$ & $2766.59 \pm 390.62^{\mathrm{cd} *}$ \\
\hline $\mathbf{0 . 3}$ & $11561.76 \pm 871.13^{\mathrm{c}}$ & $34.18 \pm 2.58^{\mathrm{c} *}$ & $4977.08 \pm 452.75^{\mathrm{c} *}$ \\
\hline $\mathbf{0 . 4}$ & $18372.47 \pm 1384.30^{\mathrm{b}}$ & $57.86 \pm 4.36^{\mathrm{b} *}$ & $15122.34 \pm 3077.53^{\mathrm{b}}$ \\
\hline $\mathbf{0 . 5}$ & $38997.32 \pm 2938.29^{\mathrm{a}}$ & $258.23 \pm 19.46^{\mathrm{a} *}$ & $38618.38 \pm 7031.14^{\mathrm{a}}$ \\
\hline
\end{tabular}

\subsection{Determination of polycylic aromatic structure}

The fluorescence of crude oils derives from the presence of PAHs formed by combinations of one or more highly fluorescent benzene rings (Abbas, 2006; Vo-Dinh, 1984). In synchronous spectra, compounds with different numbers of fused aromatic rings exhibit their maximum emissions at particular wavelengths (Kister et al., 1996). According to the number of aromatic rings, the US EPA priority $\mathrm{PAH}$ compounds are divided into three groups, representing two-, and three-, four-, and five-, and moreringed PAHs (Law, 1981). SUVF values obtained from Batman crude oil and the control and the experimental samples shown in Fig.1 and Fig.2 Petroleum hydrocarbons in crude oil and light refined products are dominated by the lowest molecular weight PAHs with only trace levels of the penta- and hexa- aromatics present. However, 1-2 rings $\mathrm{PAHs}$ have not been encountered in our control and plant samples. It appears likely that the more volatile PAHs are rapidly lost in growth media, through evaporation and photooxidation (Fig. 2). Similarly, at the $0.05 \%$ oil applications $3-4$ rings $\mathrm{PAHs}$ have not been encountered in both the control and experimental samples (Fig. 2). For oil concentrations $0.1-0.5 \%$, the intensity of 3-4 ring PAHs was lower than the control, especially at $0.1 \%$ and $0.2 \%$ oil applications (Fig. 2). Similar results were also found in our previous study (Kosesakal et al., 2015). Thus, it could be said that the bioremediation capacity of $A$. filiculoides on crude oil is much better especially at lower concentrations.

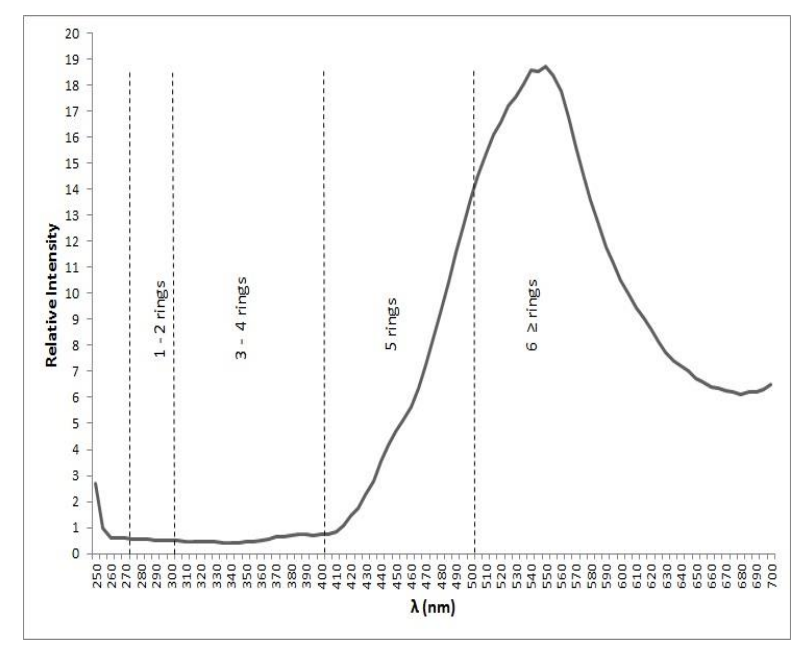

Figure 1. Synchronous excitation/emission $(\mathrm{nm})$ fluorescence spectra of aromatic hydrocarbon fractions of Batman crude oil. 


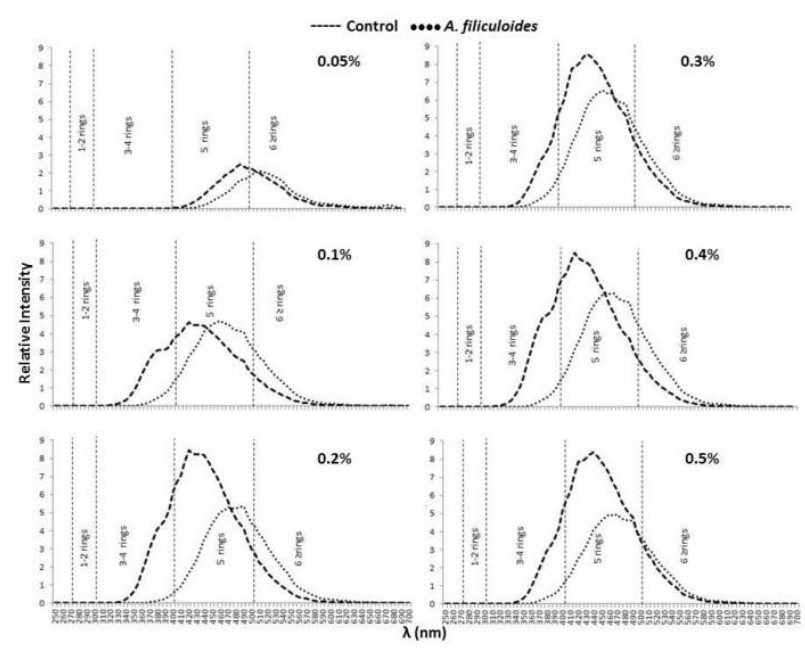

Figure 2. Synchronous excitation/emission $(\mathrm{nm})$ fluorescence spectra of aromatic hydrocarbon fractions of the control and plant samples at $0.05 \%-0.5 \%$ crude oil concentrations.

\subsection{PAHs and alkylated homologous PAHs}

At the end of the experimental period, in order to elucidate the behavior of the oil at applied concentrations in experimental and control samples, GC-MS analysis were carried out. PAHs and alkylated homologous of PAHs in control and experimental samples were determined by library screening of the chromatograms (Table 3 and 4). $\mathrm{PAH}$ compounds are relatively stable and the distribution of alkylated $\mathrm{PAH}$ homologues have been used as environmental fate indicators (Boehm et al., 1997). Generally, the degree of $\mathrm{PAH}$ degradation decreases with increasing ring size and within a homologous series and decreases with increasing alkylation (Barakat et al., 2001). In control samples, while the C0, C1 naphthalene compounds have not been encountered, C2 and C3 naphthalene compounds were determined at higher oil concentrations, $0.2 \%-0.5 \%$ (Table 3 ). On the other hand, for the experimental samples, while C0, C1, C2, naphthalene compounds have not been encountered only C3 naphthalene compounds were measured at the applied oil (0.05\%-0.5\%) concentrations (Table 4).

Table 3. PAHs and alkylated homologous PAHs determined in control samples at $(0.05 \%-0.5 \%)$ crude oil concentrations (-: not determined).

\begin{tabular}{|c|c|c|c|c|c|c|c|c|}
\hline \multirow[b]{2}{*}{ Compound } & \multirow[b]{2}{*}{$\begin{array}{c}\text { Ring } \\
\text { numbers }\end{array}$} & \multirow[b]{2}{*}{$\begin{array}{c}\text { Target } \\
\text { ions }\end{array}$} & \multicolumn{6}{|c|}{ Control } \\
\hline & & & $0.05 \%$ & $0.1 \%$ & $0.2 \%$ & $0.3 \%$ & $0.4 \%$ & $0.5 \%$ \\
\hline \multicolumn{9}{|l|}{ Naphthalene } \\
\hline C0-naphthalene & 2 & 128 & - & - & - & - & - & - \\
\hline C1-naphthalenes & 2 & 142 & - & - & - & - & - & - \\
\hline C2-naphthalenes & 2 & 156 & - & - & - & - & + & + \\
\hline C3-naphthalenes & 2 & 170 & - & - & + & + & + & + \\
\hline C4-naphthalenes & 2 & 184 & - & - & - & - & - & - \\
\hline \multicolumn{9}{|l|}{ Phenanthrenes } \\
\hline C0-phenanthrene & 3 & 178 & + & + & + & + & + & + \\
\hline C1-phenanthrenes & 3 & 192 & + & + & + & + & + & + \\
\hline C2-phenanthrenes & 3 & 206 & + & + & + & + & + & + \\
\hline C3-phenanthrenes & 3 & 220 & + & + & + & + & + & + \\
\hline C4-phenanthrenes & 3 & 234 & + & + & + & + & + & + \\
\hline \multicolumn{9}{|l|}{ Dibenzothiophenes } \\
\hline C0-dibenzothiophene & 3 & 184 & + & + & + & + & + & + \\
\hline C1-dibenzothiophenes & 3 & 198 & + & + & + & + & + & + \\
\hline C2-dibenzothiophenes & 3 & 212 & - & - & - & - & - & - \\
\hline C3-dibenzothiophenes & 3 & 226 & - & - & - & - & - & - \\
\hline \multicolumn{9}{|l|}{ Fluorenes } \\
\hline Co-fluorene & 3 & 166 & - & - & - & - & - & + \\
\hline C1-fluorenes & 3 & 180 & - & + & + & + & + & + \\
\hline C2-fluorenes & 3 & 194 & + & + & + & + & + & + \\
\hline C3-fluorenes & 3 & 208 & - & - & - & - & - & - \\
\hline \multicolumn{9}{|l|}{ Chrysenes } \\
\hline Co-chrysene & 4 & 228 & - & - & - & - & - & - \\
\hline C1-chrysenes & 4 & 242 & - & - & - & - & - & - \\
\hline C2-chrysenes & 4 & 256 & - & - & - & - & - & - \\
\hline C3-chrysenes & 4 & 270 & - & - & - & - & - & - \\
\hline Pyrene & 4 & 202 & - & - & - & - & + & + \\
\hline
\end{tabular}


Table 4. PAHs and alkylated homologous $\mathrm{PAHs}$ determined in plant samples at $(0.05 \%-0.5 \%)$ crude oil concentrations (-: not determined).

\begin{tabular}{|c|c|c|c|c|c|c|c|c|}
\hline \multirow[b]{2}{*}{ Compound } & \multirow[b]{2}{*}{$\begin{array}{c}\text { Ring } \\
\text { numbers }\end{array}$} & \multirow[b]{2}{*}{$\begin{array}{c}\text { Target } \\
\text { ions }\end{array}$} & \multicolumn{6}{|c|}{ A. filiculoides } \\
\hline & & & $0.05 \%$ & $0.1 \%$ & $0.2 \%$ & $0.3 \%$ & $0.4 \%$ & $0.5 \%$ \\
\hline \multicolumn{9}{|l|}{ Naphthalene } \\
\hline C0-naphthalene & 2 & 128 & - & - & - & - & - & - \\
\hline C1-naphthalenes & 2 & 142 & - & - & - & - & - & - \\
\hline C2-naphthalenes & 2 & 156 & - & - & - & - & - & - \\
\hline C3-naphthalenes & 2 & 170 & + & + & + & + & + & + \\
\hline C4-naphthalenes & 2 & 184 & - & - & - & - & - & - \\
\hline \multicolumn{9}{|l|}{ Phenanthrenes } \\
\hline C0-phenanthrene & 3 & 178 & + & + & + & + & + & + \\
\hline C1-phenanthrenes & 3 & 192 & + & + & + & + & + & + \\
\hline C2-phenanthrenes & 3 & 206 & + & + & + & + & + & + \\
\hline C3-phenanthrenes & 3 & 220 & + & + & + & + & + & + \\
\hline C4-phenanthrenes & 3 & 234 & + & + & + & + & + & + \\
\hline \multicolumn{9}{|l|}{ Dibenzothiophenes } \\
\hline C0-dibenzothiophene & 3 & 184 & - & - & - & - & - & - \\
\hline C1-dibenzothiophenes & 3 & 198 & - & - & - & + & + & + \\
\hline C2-dibenzothiophenes & 3 & 212 & - & - & - & - & - & - \\
\hline C3-dibenzothiophenes & 3 & 226 & - & - & - & - & - & - \\
\hline \multicolumn{9}{|l|}{ Fluorenes } \\
\hline Co-fluorene & 3 & 166 & - & - & - & - & - & + \\
\hline C1-fluorenes & 3 & 180 & - & - & + & + & + & + \\
\hline C2-fluorenes & 3 & 194 & - & - & - & - & + & + \\
\hline C3-fluorenes & 3 & 208 & - & - & - & - & - & - \\
\hline \multicolumn{9}{|l|}{ Chrysenes } \\
\hline C0-chrysene & 4 & 228 & - & - & - & - & - & - \\
\hline C1-chrysenes & 4 & 242 & - & - & - & - & - & - \\
\hline C2-chrysenes & 4 & 256 & - & - & - & - & - & - \\
\hline C3-chrysenes & 4 & 270 & - & - & - & - & - & - \\
\hline Pyrene & 4 & 202 & - & - & - & - & - & - \\
\hline
\end{tabular}

Phenanthrene and alkylated homologues were determined in both control (Table 3) and experimental (Table 4) samples. Briefly, in this study, naphthalene and alkylated naphthalenes and phenanthrene and alkylated phenanthrenes were determined in both experimental and control samples. On the other hand, dibenzothiophenes, alkylated dibenzothiophenes, fluorenes and alkylated fluorenes have not been encountered in the experimental samples at $0.05 \%$ and $0.1 \%$ oil applications. Thus, it could be concluded that although the SUVF technique is a useful tool to determine polycyclic aromatic structure of a compound, GC/MS provides more precise data for the characterization of the present aromatic compounds.

\section{Conclusion}

In conclusion, the contribution of $A$. filiculoides to the biodegradation of PAHs was not significant at dense oil contaminations. Furthermore, the bioremediative capacity of $A$. filiculoides for PAHs strongly depends on the concentration of crude oil and its toxicity to the plants. Results from this study indicated that Azolla filiculoides is likely to be more effective at lower oil concentrations for the phytoremediation of crude oil-contaminated freshwater areas.

\section{Acknowledgements}

This work was supported by Istanbul University Research Fund (Project No: 2227 and 31405).

\section{References}

Abbas O., Rébufa C., Dupuy N., Permanyer A., Kister J. and Azevedo D.A. (2006), Application of chemometric methods to synchronous UV fluorescence spectra of petroleum oils, Fuel, 85, 2653-2661.

Al-Baldawi I.A., Abdullah S.R.S., Anuar N., Suja F. and Mushrifah I. (2015), Phytodegradation of total petroleum hydrocarbon (TPH) in diesel-contaminated water using Scirpus grossus, Ecological Engineering, 74, 463-473.

Aljuboury D.A.D.A., Palaniandy P., Abdul Aziz H.B. and Feroz S. (2017), Treatment of petroleum wastewater by conventional and new technologies - A review, Global NEST Journal, 19(3), 439-452.

Baek K.-H., Kim H.-S., Oh H.-M., Yoon B.-D., Kim J. and Lee I.-S. 2004, Effects of crude oil, oil components, and bioremediation on plant growth, Journal of Environmental 
Science and Health. Part A, Toxic/hazardous Substances \& Environmental Engineering, 39(9), 2465-2472.

Barakat A.O., Qian Y., Kim M. and Kennicutt M.C. (2001), Chemical characterization of naturally weathered oil residues in arid terrestrial environment in Al-Alamein, Egypt, Environmental International, 27, 291-310.

Boehm P.D., Douglas G.S., Burns W.A. Mankiewicz P.J., Page D.S. and Bence E. (1997), Application of petroleum hydrocarbon chemical fingerprinting and allocation techniques after the Exxon Valdez oil spill, Marine Pollution Bulletin, 34, 599-613.

Effendi, H., Munawaroh, A. and Ayu, I.P. (2017), Crude oil spilled water treatment with Vetiveria zizanioides in floating wetland, The Egyptian Journal of Aquatic Research, 43, 185193.

Ehrhardt M.G., Burns K.A. and Bicego M.C. (1992), Sunlightinduced compositional alterations in the seawater-soluble fraction of a crude oil, Marine Chemistry, 37, 53-64.

Ertekin O., Kosesakal T., Unlu V.S., Dagli S., Pelitli V., Uzyol H., Tuna Y., Kulen O., Yuksel B., Onarici S., Keskin B.C. and Memon A. (2015), Phytoremediation potential of Landoltia punctata on petroleum hydrocarbons, Turkish Journal of Botany, 39, 23-29.

Gomes M.P., de Brito J.C.M., Carvalho Carneiro M.M.L., Ribeiro da Cunha M.R., Garcia Q.S. and Figueredo C.C. (2018.), Responses of the nitrogen-fixing aquatic fern Azolla to water contaminated with Ciprofloxacin: Impacts on biofertilization, Environmental Pollution, 232, 293-299.

Haritash A.K., Kaushik C.P. (2009), Biodegradation aspects of polycyclic aromatic hydrocarbons (PAHs): A review, Journal of hazardous materials, 169, 1-15.

Huang X-D., El-Alawi Y., Gurska J., Glick B.R. and Greenberg B.M. (2005), A multi-process phytoremediation system for decontamination of persistent total petroleum hydrocarbons (TPHs) from soils, Microchemical Journal, 81, 139-147.

Jagtap S.S., Woob S.M., Kim T-S., Dhiman S.S., Kim D. and Lee J-K. (2014), Phytoremediation of diesel-contaminated soil and saccharification of the resulting biomass, Fuel, 116, 292-298.

Jampeetong A. and Brix H. (2009), Effects of $\mathrm{NH}^{+}$concentration on growth, morphology, and $\mathrm{NH}^{+}$uptake kinetics of Salvinia natans, Ecological Engineering, 35, 695-702.

Kister J., Pieri N., Álvarez R., Díez M.A. and Pis J.J. (1996), Effects of preheating and oxidation on two bituminous coals assessed by synchronous UV fluorescence and FTIR spectroscopy, Energy Fuels, 10, 948-957.

Kollah B., Patra A.K. and Mohanty S.R. (2016), Aquatic microphylla Azolla: a perspective paradigm for sustainable agriculture, environment and global climate change, Environmental Science and Pollution Research, 23(5): 43584369.

Kosesakal T., Unal M., Kulen O., Memon A. and Yuksel, B. (2016), Phytoremediation of petroleum hydrocarbons by using a freshwater fern species Azolla filiculoides Lam., International Journal of Phytoremediation, 18(5), 467-476.

Kosesakal T., Unlu V.S., Kulen O., Memon A. and Yuksel, B. (2015), Evaluation of the phytoremediation capacity of Lemna minor L. in crude oil spiked cultures, Turkish Journal of Biology, 39, 1-6.

Law R.J. (1981), Hydrocarbon concentrations in water and sediments from UK marine waters, determined by fluorescence spectroscopy, Marine Pollution Bulletin, 12, 153-157.
Lloyd J.B.F. (1971), The nature and evidential value of the luminescence of automobile engine oils and related materials. I. Synchronous excitation of fluorescence emission, Journal - Forensic Science Society, 11, 83-94.

Millioli V.S., Servulo E-L.C., Sobral L.G.S., De Carvalho D.D. (2009), Bioremediation of crude oil-bearing soil: Evaluating the effect of rhamnolipid addition to soil toxicity and to crude oil biodegradation efficiency, Global NEST Journal, 11(2), 181-188.

Mrayyan B. and Battikhi M.N. (2005), Biodegradation of total organic carbons (TOC) in Jordanian petroleum sludge, Journal of Hazardous Materials, B120(1-3), 127-134.

Okoh A.I. (2006), Biodegradation alternative in the cleanup of petroleum hydrocarbon pollutants, Microbiology and Molecular Biology Reviews: MMBR, 1(2), 38-50.

Peng S., Zhou Q., Cai Z. and Zhang Z. (2009), Phytoremediation of petroleum contaminated soils by Mirabilis jalapa L. in a greenhouse plot experiment, Journal of Hazardous Materials, 168, 1490-1496.

Propst T.L., Lochmiller R.L., Qualls C.W. and Mcbee K. (1999), In situ (mesocosm) assessment of immunotoxicity risk to small mammals inhabiting petrochemical waste sites, Chemosphere, 38, 1049-1067.

Rajkumar M., Prasad M.N.V., Swaminathan S. and Freitas H. (2013), Climate change driven plant-metal-microbe interactions, Environmental International, 53, 74-86.

Vasudevan N. and Rajaram P. (2001), Bioremediation of oil sludge contaminated soil, Environmental International, 26, 409-411.

Vo-Dinh T., Bruewer T.J., Colovos G.C., Wagner J. and Jungers R.H. (1984), Field evaluation of a cost-effective screening procedure for polynuclear aromatic pollutants in ambient air samples, Environmental Science \& Technology, 18, 477-482.

Wang F., Yi X., Qu H., Chen L., Liu D., Wang P. and Zhou Z. (2017), Enantioselective accumulation, metabolism and phytoremediation of lactofen by aquatic macrophyte Lemna minor, Ecotoxicology and Environmental Safety, 143, 186192.

Zappi M.E., Rogers B.A., Teeter C.L., Gunnison D. and Bajpai R. (1996), Bioslurry treatment of a soil contaminated with low concentrations of total petroleum hydrocarbons, Journal of Hazardous Materials, 46, 1-12. 